\title{
Distribution of Anthocyanins Delivered from a Bioadhesive Black Raspberry Gel Following Topical Intraoral Application in Normal Healthy Volunteers
}

\author{
Carlos M. Ugalde, ${ }^{1}$ Zhongfa Liu, ${ }^{4}$ Chen Ren, ${ }^{4}$ Kenneth K. Chan, ${ }^{4,5}$ Kapila A. Rodrigo, ${ }^{1}$ Yhonghua Ling, ${ }^{4}$ \\ Peter E. Larsen, ${ }^{1}$ Guillermo E. Chacon, ${ }^{1}$ Gary D. Stoner, ${ }^{3,5}$ Russell J. Mumper, ${ }^{6}$ \\ Henry W. Fields, ${ }^{2}$ and Susan R. Mallery ${ }^{1,5,7}$
}

Received September 8, 2008; accepted December 3, 2008; published online January 10, 2009

\begin{abstract}
Purpose. Results from our oral cavity chemoprevention trial demonstrated appreciable interpatient variations regarding chemopreventive efficacy of a freeze dried black raspberry (FBR) gel. We speculated these data reflected individual patient-related differences in absorption, target tissue uptake and local compound metabolism of key FBR compounds (anthocyanins). Accordingly, this study assessed the distribution of anthocyanins from the $10 \%(w / w)$ FBR gel in saliva, oral tissues and plasma.

Methods. Human subject participation entailed collection of: (1) saliva, tissue and plasma (5 min following gel application, keratinized tissues), (2) saliva and plasma (5 min after sublingual gel application), (3) saliva and plasma at 1,2, and $4 \mathrm{~h}$ post gel application (keratinized tissues), and (4) saliva (cyanidin 3-rutinoside incubations). Levels of FBR anthocyanins in the respective samples were analyzed by LC/MS/MS.

Results. Our data show: significantly higher anthocyanin levels in saliva and oral tissues relative to matched plasma samples, marked donor-specific variations in anthocyanin uptake, sustainability of anthocyanins at the target site, $\mathrm{pH}$ affects anthocyanin penetration and intraoral anthocyanin decomposition and/or metabolism.

Conclusions. No previous oral cavity chemoprevention trials evaluated compound distribution at the treatment site. Our data, which demonstrate a local delivery-derived pharmacologic advantage, provide insights which could advance oral cavity chemoprevention strategies.
\end{abstract}

KEY WORDS: anthocyanins; black raspberries; chemoprevention; local delivery; oral cancer.

\section{INTRODUCTION}

Oral squamous cell carcinoma (oral SCC), which arises from dysplastic surface epithelium lining the mouth, comprises $90 \%$ of oral cavity cancers (1). Analogous to other carcinomas, oral SCCs do not arise de novo, but develop through a series of progressive perturbations in the overlying epithelium (1). Management for oral SCC entails wide surgical excision, and may also include intra and/or post-

\footnotetext{
${ }^{1}$ Division of Oral Maxillofacial Surgery, Pathology \& Anesthesiology, College of Dentistry, The Ohio State University, Columbus, Ohio, USA.

${ }^{2}$ Division of Orthodontics, College of Dentistry, The Ohio State University, Columbus, Ohio, USA.

${ }^{3}$ Department of Internal Medicine, College of Medicine, The Ohio State University, Columbus, Ohio, USA.

${ }^{4}$ College of Pharmacy, The Ohio State University, Columbus, Ohio, USA.

${ }^{5}$ The Ohio State University Comprehensive Cancer Center, The Ohio State University, Columbus, Ohio, USA.

${ }^{6}$ Division of Molecular Pharmaceutics, School of Pharmacy, University of North Carolina at Chapel Hill, Chapel Hill, North Carolina, USA.

${ }^{7}$ To whom correspondence should be addressed. (e-mail: mallery.1@ osu.edu)
}

operative radiation therapy $(2,3)$. Despite these aggressive treatments, the overall survival rates for oral SCCs remain among the lowest of major cancers (4). Clearly, prevention of oral SCC development by inhibiting malignant transformation of dysplastic oral lesions could be beneficial. The current standard of care for precancerous oral lesions entails clinical monitoring in conjunction with either surgical excision or laser ablation for more histologically advanced (moderate dysplasia or higher) lesions (1). Notably, approximately one third of oral dysplastic lesions recur despite complete excision with microscopically confirmed clear margins $(5,6)$. Further while not all oral epithelial dysplasias progress to oral SCC, we are currently unable to determine which lesions will undergo malignant transformation (6).

Chemoprevention, which is defined as the use of naturally or synthetically derived compounds to promote regression or prevent progression of premalignant lesions, represents a promising oral cancer prevention strategy (7). Because it is visibly accessible, the mouth has two significant aspects that facilitate chemoprevention. First, clinicians can directly monitor the response of lesional tissues during treatment. Secondly, topical approaches are feasible because patients can see their lesions - a factor that facilitates agent application to the target site. 
To date, the majority of oral cancer chemoprevention trials have employed systemic administration of the study compounds (8-12). Due to the established differentiationinducing effects of retinoids, vitamin $\mathrm{A}$ and retinoic acid derivatives represent some of the most intensely evaluated oral cavity chemopreventive agents (8-12). These results, however, have been disappointing (8-12). Plausible explanations for the suboptimal results included the relative recalcitrance of the oral cavity lesions to treatment and the apparent inability to obtain therapeutically effective local levels without inducing systemic toxicities (8-12). Previous local delivery attempts for oral cavity chemoprevention have also encountered difficulties $(13,14)$. The ONYX-15 trial, which evaluated a mouthwash that targeted p53 defective cells, initially showed efficacy (13). This study, however, was discontinued after a trial participant developed circulating antibodies against the adenoviral vector used to target the p53 defective oral epithelial cells (13). Results from the mouthwash trial that evaluated the cyclooxygenase inhibitor ketorolac showed that while both the placebo and active rinses were well-tolerated, the active formulation provided no significant reductions in the extent of leukoplakia (14).

Our labs have shown that freeze dried black raspberries (FBR) convey chemopreventive effects at both the in vitro and in vivo levels (15-19). Recently, we developed a prototype mucoadhesive gel that contained FBR for evaluation as a prospective oral cavity chemopreventive agent (20). The FBR content of the prototype gel was increased from $5 \%$ to $10 \% \mathrm{w} / \mathrm{w}$ and the $\mathrm{pH}$ was reduced to 3.5 to preserve the anthocyanins in the more stable flavylium cation form for use in our recently completed Phase I/II chemoprevention trial. Treatment entailed topical gel application to oral dysplastic lesions $(0.5 \mathrm{~g}$ four-times per day for 6 weeks) $(21,22)$. Trial results show that gel application significantly reduced loss of heterozygosity indices at loci associated with tumor suppressor genes, suppressed genes associated with RNA processing, growth factor recycling and inhibition of apoptosis and significantly reduced cyclooxygenase two levels in treated lesional epithelium $(21,22)$.

Our clinical trial data also showed extensive interpatient differences with regard to agent responsiveness $(21,22)$. We speculate that these variations reflect differences in local pharmacokinetics with factors such as absorption, penetration, and potentially FBR metabolism all impacting therapeutic outcomes. The purposes of the current study were to determine: (1) whether topical FBR gel provides a pharamacologic advantage i.e. deliver higher levels of therapeutic compounds at the local treatment site relative to systemic levels, (2) distribution and possible sustainability of FBR anthocyanins following topical intraoral FBR gel application. Our findings show compound compartmentalization at the targeted site with highest levels obtained in saliva, intermediate levels in tissues, and non-detectable levels in plasma, considerable interdonor heterogeneity with regard to saliva and tissue levels achieved, and donor-related variations in gel absorptive capacity. Similarly, the time course and sublingual application site studies show appreciable interdonor variations with regard to therapeutic compound i.e. FBR anthocyanin retention in saliva and confirm negligible systemic uptake from intraoral tissue locations.

\section{MATERIALS AND METHODS}

Berry Gel Manufacturing. The bioadhesive gels used in these studies were prepared using current Good Manufacturing Practices (cGMP) at the cGMP facility within the Center for Pharmaceutical Science and Technology at the University of Kentucky, Lexington, KY. The quality control measures and details of the gel composition and method of manufacture have been described previously (20). Briefly, the gel composition used for the clinical trial consisted of (percent $w / w$ ): Noveon AA1 (NF) (Noveon, Inc., Cleveland, $\mathrm{OH}) 1.35 \%$, Carbopol 971P (NF) (BF Goodrich Specialty Chemicals, Cleveland, $\mathrm{OH}$ ) $1.575 \%$, glycerin (USP) $1.0 \%$, edentate disodium (USP) $0.1 \%$, 2-phenoxyethanol (BP) $1.0 \%$, benzyl alcohol (USP) $1.0 \%$, FBR $10 \%$, and purified water to reach $100 \%$ (20). For the clinical trial, and this current study, the prototype gel's FBR concentration was increased to $10 \%(w / w)$ and the $\mathrm{pH}$ was fixed at $\mathrm{pH} 3.5$ to stabilize the more biologically active flavylium cation of the anthocyanin molecules for the clinical trial $(21,22)$.

Human Subjects' Participation. Thirty total human subjects participated in this study which was approved by The Ohio State University Institutional Review Board. Twenty three adults, who were undergoing elective oral surgical procedures, were consented to participate in the tissue compartmentalization studies. Three of these consented donors (001, 003 and 022) did not complete study participation due to difficulty in obtaining adequate saliva volumes for analyses. Exclusion criteria for this component of the study included partially erupted mandibular third molars, or any sign of ulceration or inflammation in the tissue overlying these teeth. The retromolar pad tissue was dried, then $0.5 \mathrm{~g}$ of gel was massaged at the site for $30 \mathrm{~s}$ to facilitate uptake. Five minutes after gel application, saliva (collected for $1 \mathrm{~min}$ ) and peripheral blood samples were obtained. The gel treated tissue overlying the third molar was then removed for surgical access. A second, single time point study entailed sublingual application of $0.5 \mathrm{~g}$ gel in five donors, followed by collection of saliva and plasma 5 min following gel application. A third aspect of the study consisted of time course analyses in which plasma and saliva samples were obtained from five donors at baseline (plasma only), 1, $2 \mathrm{~h}$ (saliva only) and 1 and $4 \mathrm{~h}$ (plasma) following application of $0.5 \mathrm{~g}$ FBR gel to the retromolar pad. Donors in the time course studies had free access to liquids following gel application. The demographics of the human subject participants are presented in Tables I, II, III, and IV.

All subjects completed a food history sheet which addressed consumption and quantity of anthocyanin-rich foods such as berries, cherries, purple grapes and red wine, for the $24 \mathrm{~h}$ that preceded their study participation. While some of the study participants reported a modest recent consumption of some anthocyanin-rich foods, baseline samples from these donors revealed nondetectable saliva or plasma levels prior to gel application.

Handling of the Saliva, Plasma and Tissue Samples. Volumes of the saliva samples were recorded, followed by addition of formic acid (5\% final concentration). Peripheral 
Table I. Demographic Data of Participants for the Saliva, Tissue and Plasma Analyses

\begin{tabular}{|c|c|c|c|c|}
\hline Donor & Age & Gender & $\begin{array}{l}\text { Daily medications and } \\
\text { effect(s) on saliva }\end{array}$ & $\begin{array}{l}\text { Intraoperative medications } \\
\text { and } \operatorname{effect}(\mathrm{s}) \text { on saliva }\end{array}$ \\
\hline STP002 & 29 & $\mathrm{~F}$ & None & None \\
\hline STP004 & 25 & $\mathrm{~F}$ & $\begin{array}{l}\text { Loratadine (decrease) } \\
\text { Albuterol (decrease) }\end{array}$ & Nitrous oxide (none) \\
\hline STP005 & 25 & $\mathrm{~F}$ & $\begin{array}{l}\text { Sertraline (decrease) } \\
\text { Propanolol (decrease) }\end{array}$ & None \\
\hline STP006 & 18 & $\mathrm{~F}$ & None & None \\
\hline STP007 & 20 & M & None & $\begin{array}{l}50 \mu \mathrm{g} \text { fentanyl (decrease) } \\
2 \mathrm{mg} \text { midazolam (increase) }\end{array}$ \\
\hline STP008 & 30 & $\mathrm{~F}$ & None & None (none) \\
\hline STP009 & 25 & M & None & $\begin{array}{l}2 \mathrm{mg} \text { midazolam (increase) } \\
25 \mu \mathrm{g} \text { fentanyl (decrease) } \\
5 \mathrm{mg} \text { diazepam (increase) }\end{array}$ \\
\hline STP010 & 22 & $\mathrm{~F}$ & None & $\begin{array}{l}10 \mathrm{mg} \text { diazepam (increase) } \\
25 \mathrm{mg} \text { Demerol (decrease) }\end{array}$ \\
\hline STP011 & 20 & M & $\begin{array}{l}\text { Clopidrogel, aspirin, nabumetone, somatropin, } \\
\text { methylprednisolone }\end{array}$ & $1 \mathrm{mg}$ midazolam (increase) \\
\hline & & & & $25 \mu \mathrm{g}$ fentanyl (decrease) \\
\hline STP012 & 25 & $\mathrm{~F}$ & $\begin{array}{l}\text { Lamotrigine (decrease) } \\
\text { Medroxyprogesterone }\end{array}$ & $\begin{array}{l}15 \mathrm{mg} \text { diazepam (increase) } \\
50 \mathrm{mg} \text { Demerol (decrease) }\end{array}$ \\
\hline STP013 & 22 & M & None & $\begin{array}{l}15 \mathrm{mg} \text { diazepam (increase) } \\
50 \mathrm{mg} \text { Demerol (decrease) }\end{array}$ \\
\hline STP014 & 25 & $\mathrm{~F}$ & None & $\begin{array}{l}15 \mathrm{mg} \text { diazepam (increase) } \\
50 \mathrm{mg} \text { Demerol (decrease) }\end{array}$ \\
\hline STP015 & 31 & M & None & $\begin{array}{l}2 \mathrm{mg} \text { midazolam (increase) } \\
50 \mu \mathrm{g} \text { fentanyl (decrease) } \\
5 \mathrm{mg} \text { diazepam (increase) }\end{array}$ \\
\hline STP016 & 31 & M & None & $\begin{array}{l}50 \mu \mathrm{g} \text { fentanyl (decrease) } \\
1 \mathrm{mg} \text { midazolam (increase) }\end{array}$ \\
\hline STP017 & 26 & $\mathrm{~F}$ & Birth control pills & None \\
\hline STP018 & 23 & M & None & $\begin{array}{l}25 \mu \mathrm{g} \text { fentanyl (decrease) } \\
2 \mathrm{mg} \text { midazolam (increase) }\end{array}$ \\
\hline STP019 & 25 & $\mathrm{~F}$ & None & None \\
\hline STP020 & 23 & M & Vitamins & $\begin{array}{l}2 \mathrm{mg} \text { midazolam (increase) } \\
50 \mu \mathrm{g} \text { fentanyl (decrease) } \\
5 \mathrm{mg} \text { diazepam (increase) }\end{array}$ \\
\hline STP021 & 25 & $\mathrm{~F}$ & Vitamins & $\begin{array}{l}10 \mathrm{mg} \text { diazepam (increase) } \\
50 \mathrm{mg} \text { Demerol (decrease) }\end{array}$ \\
\hline STP022 & 34 & $\mathrm{~F}$ & None & $\begin{array}{l}5 \mathrm{mg} \text { diazepam (increase) } \\
50 \mathrm{mg} \text { Demerol (decrease) }\end{array}$ \\
\hline STP023 & 22 & $\mathrm{~F}$ & None & Nitrous oxide (None) \\
\hline
\end{tabular}

AHFS Drug Information ${ }^{\circledR} 2008$ (http://www.ahfsdruginformation.com) was used to determine the effects of medications on saliva

blood samples were centrifuged, plasma volumes recorded, followed by addition of formic acid. Following acidification, saliva and plasma samples were stored at $-80^{\circ} \mathrm{C}$ until LC/MS/ MS analyses. The human tissue samples comprised of surface epithelium and associated connective tissue were immediately placed in formic acid and stored at $-80^{\circ} \mathrm{C}$ until preparation for the LC-MS/MS analyses. Prior to analyses, tissues were washed with phosphate buffered saline (PBS), homogenized on ice, and aliquots removed for protein determination via the Lowry assay (23). To facilitate tissue preparation to constituent components, homogenized samples were subsequently treated with trypsin $2.5 \%$ and collagenase I $2.0 \%$ (Worthington Biochemical Corporation, Lakewood, New Jersey) for $1.5 \mathrm{~h}$ at $37^{\circ} \mathrm{C}$, followed by acidification with

Table II. Demographic Data of Participants for the Time Course Saliva and Plasma Analyses

\begin{tabular}{lcll}
\hline Donor & Age & Gender & \\
\hline TC001 & 54 & F & Montelukast, Azelastine \\
TC002 & 61 & M & Atenolol, Atorvastatin, Clopidogrel, Acetylsalicylic acid, Ezetimibe, Rabeprazole, Fosinopril \\
TC003 & 27 & M & None \\
TC004 & 26 & M & None \\
TC005 & 29 & M & Finasteride \\
\hline
\end{tabular}

AHFS Drug Information $® 2008$ (http://www.ahfsdruginformation.com) was used to determine the effects of medications on saliva 
Table III. Demographic Data of Participants for the Sublingual, Single Time Point Saliva and Plasma Analyses

\begin{tabular}{lccc}
\hline Donor & Age & Gender & Prescription Medications \\
\hline ST001 & 22 & M & Fexofenadine \\
ST002 & 20 & M & None \\
ST003 & 30 & M & None \\
ST004 & 39 & F & Estrogen patch, vitamin B \\
ST005 & 28 & M & None \\
\hline
\end{tabular}

formic acid. To assess the effects of this tissue processing protocol on anthocyanin stability, additional studies were conducted which entailed addition of known amounts of cyanidin 3-rutinoside ( $500 \mathrm{ng} / \mathrm{ml}$ and $32 \mu \mathrm{g} / \mathrm{ml}$ ) to control oral mucosal tissues prior to preparation. Saliva levels were reported as total anthocyanins, while tissue and plasma were reported as nanograms per milligram protein and micrograms per milliliter, respectively.

LC/MS/MS Analyses to Determine Levels of FBR Anthocyanins in the Human Samples. Anthocyanins were selected as the targeted compounds for the PK analyses for two reasons. First, anthocyanins are the predominant phenolic compounds in FBR (24). Secondly, our labs have shown that anthocyanin-enriched FBR extracts possess high chemopreventive impact (25). The four FBR anthocyanins (highest to lowest levels, respectively) are: cyanidin 3-rutinoside, cyanidin 3xylosylrutinoside, cyanidin 3-sambubioside, and cyanidin 3glucoside. Cyanidin 3-glucoside, malvidin 3-glucoside, cyanidin 3-sambubioside, and cyanidin 3-rutinoside standards were obtained from Polyphenols Laboratory AS (Hanaveien 4-6, N4327, Sandens, Norway). Malvidin 3-glucoside was selected as the internal standard as described previously by Stoner et al. (26). Due to the lack of a standard for cyanidin 3-xylosylrutinoside, the calibration curve of cyanidin 3-rutinoside was used with an ion transition channel at $m / z, 727.00>287.00(E=35 \%)$. The standards and the human samples were analyzed using a TSQ quantum triple mass spectrometer (ThermoFinnigan, San Jose, CA) under an electrospray ionization (ESI) positive mode (standard curves ranged from 1 to $1,000 \mathrm{ng} / \mathrm{ml}, R^{2}>0.99$ ). The mean accuracies between and within runs were $>98 \%$, with an average coefficient of variance around $8 \%$. The minimum detectable levels for the $4 \mathrm{FBR}$ anthocyanins were $0.2 \mathrm{ng} / \mathrm{ml}$ in $0.4 \mathrm{ng} / \mathrm{ml}$ human plasma, $1 \mathrm{ng} / \mathrm{ml}$ in $0.2 \mathrm{ml}$ diluted saliva (at least a 20 fold dilution) and $1.0 \mathrm{ng} / \mathrm{ml}$ for tissue homogenates. Prior to sample analyses, the analytical methods were validated for detection of the FBR anthocyanins in human saliva, plasma and tissues by using internal standards "spiked" with human saliva, plasma and tissue, respectively.

Determination of the Effect of Human Saliva on Cyanidin 3-Rutinoside. Results from our time course studies revealed one donor (TC001) whose saliva samples contained cyanidin 3glucoside as the predominant FBR anthocyanin. These data suggested that the predominant FBR anthocyanin (cyanidin 3rutinoside, a disaccharide containing rhamnose+glucose) was undergoing decomposition to the monosaccharide cyanidin 3glucoside (glucose only) in the oral cavity. Studies were therefore conducted on saliva collected from five donors, one of whom (SAL001) was the same donor with the unique time course saliva anthocyanin distribution (TC001) (Table IV). Four milliliters of saliva were collected from all donors, with $1 \mathrm{ml}$ to serve as the donors' baseline. Rutinoside $(50 \mu \mathrm{M}$ final concentration) was added to the remaining $3 \mathrm{ml}$, and the saliva was aliquoted into samples designated for the 1,2 , and $4 \mathrm{~h}$ time points. To account for rutinoside degradation in the absence of human salivary enzymes, rutinoside $(50 \mu \mathrm{M}$ final concentration) was placed in an artificial saliva ( $\mathrm{pH} 7.4$, reagents listed in final concentrations) which consisted of: sodium carboxymethylcellulose $(0.5 \%)$, sorbitol $(165 \mathrm{mM}), \mathrm{NaCl}(14 \mathrm{mM}), \mathrm{KCl}$ (16 mM), calcium chloride dehydrate (1.0 mM), $\mathrm{MgCl}_{2}$ $(0.63 \mathrm{mM})$, and Trizma hydrochloride $(2.0 \mathrm{mM})$. All saliva samples were incubated $\left(37^{\circ} \mathrm{C}, 5 \% \mathrm{CO}_{2}\right)$ on a gently rocking platform. At the designated time points, saliva samples were promptly acidified ( $1 \%$ formic acid, final concentration) and frozen at $-80^{\circ} \mathrm{C}$ until LC/MS/MS analyses.

Statistical Analyses. Comparisons of anthocyanin distribution in the saliva, tissue and plasma samples were conducted using a two tailed Mann Whitney $U$ test. Intradonor comparisons of anthocyanin levels contained in the donor-matched saliva and tissue samples were evaluated using a one-way Chi square analysis. Findings with $p$ values $<0.05$ were considered to be significant.

\section{RESULTS}

Levels of Anthocyanins in the 10\% FBR Gel. Anthocyanin levels in the berry gel used in the tissue-saliva-plasma analyses were $(\mathrm{ng} / \mathrm{mg}$, mean $\pm \mathrm{SD}, n=9)$ : cyanidin 3-rutinoside $(2,749.7 \pm 359.97)$, cyanidin 3-xylosylrutinoside $(1,567.7 \pm$ $108.70)$, cyanidin 3 -sambubioside $(603.5 \pm 46.89)$ and cyanidin 3 -glucoside $(536.1 \pm 54.43)$. These values, which compare favor-

Table IV. Demographic Data of Participants for the Rutinoside-Saliva Time Course Incubation Studies

\begin{tabular}{lccl}
\hline Donor & Age & Gender & Prescription medications \\
\hline SL 001 & 54 & F & Montelukast, Azelastine. Note: same donor as TC001 \\
SL 002 & 46 & F & None \\
SL 003 & 32 & M & None \\
SL 004 & 22 & M & Allegra. Note: same donor as ST001 \\
SL 005 & 20 & M & None. Note: same donor as ST002 \\
\hline
\end{tabular}


ably to the relative anthocyanin proportions found in black raspberries (24), verified that the natural black raspberry anthocyanin distribution was not perturbed during gel formulation. Similarly, the FBR anthocyanin levels in the gel used for the time course and sublingual gel application studies [(nanograms per milligram mean $+\mathrm{SD}, n=3)$ : cyanidin 3-rutinoside $(2,208.4 \pm 17.91)$, cyanidin 3-xylosylrutinoside (1,418.1 \pm 53.58$)$, cyanidin 3-sambubioside $(339.4 \pm 20.91)$ and cyanidin 3glucoside $(347.3 \pm 8.05)]$ also reflected the naturally occurring FBR anthocyanin distribution.

The retromolar pad application site, single time point analyses of saliva, plasma and tissue samples demonstrate sitespecific anthocyanin localization and appreciable interdonor variations. The respective levels of the four FBR anthocyanins contained in the saliva samples paralleled the anthocyanin distribution found in FBR and the tested gel in the majority of donors. Donor saliva volumes (milliliter) were: mean $\pm \mathrm{SEM}=$ $2.37 \pm 0.57, \min =0.50, \max =9.62$, fold difference $=19.24$. The total black raspberry anthocyanins (micrograms) retained in human saliva were: cyanidin 3-glucoside: mean $\pm \mathrm{SEM}=31.82 \pm$ $7.92, \min =1.66, \max =152.52$, fold difference $=91.89$; cyanidin 3 sambubioside: mean $=40.22 \pm 9.85, \min =1.47, \max =176.63$, fold difference $=120.16$; cyanidin 3-rutinoside: mean $=218.82 \pm 49.42$, $\min =16.49$, $\max =914.73$, fold difference $=55.47$; cyanidin 3xylosylrutinoside mean $=126.56 \pm 31.07, \min =7.17, \max =569.30$, fold difference $=79.40$. The mean percent uptake \pm SEM of the respective anthocyanins in saliva were: cyanidin 3-glucoside $=$ 14.44 \pm 3.76 ; cyanidin 3 -sambubioside $=13.33 \pm 3.27$; cyanidin 3 - rutinoside $=18.26 \pm 4.09 ;$ cyanidin 3 -xylosylrutinoside $=16.15 \pm$ 3.96 , for an overall average of $15 \%$ anthocyanin uptake in saliva.

Analyses of tissue samples for anthocyanin content also revealed extensive interdonor variations (Table V). Cyanidin 3-rutinoside and cyanidin 3-xylosylrutinoside were the highest and second highest anthocyanins detected in the tissue samples; data which conform to the relative anthocyanin distribution in FBR. Despite the fact that cyanidin 3-glucoside is present at lower concentrations in FBR that cyanidin 3-sambubioside, more donors' tissues $(n=14)$ contained cyanidin 3-glucoside and at higher mean levels than cyanidin 3-sambubioside $(n=5)$ (Table V). Three donors' tissues did not contain detectable levels of any FBR anthocyanins, while five tissue samples contained detectable levels of all four FBR anthocyanins (Table V). The majority of donors' tissues $(n=$ 9) contained three anthocyanins i.e. cyanidin 3-rutinoside, cyanidin 3-xylosylrutinoside and cyanidin 3-glucoside. Results from the anthocyanin stability tissue processing studies showed an approximate $55 \%$ and $87 \%$ cyanidin 3-rutinoside recovery in the samples that contained $500 \mathrm{ng} / \mathrm{ml}$ and $32 \mu \mathrm{g} / \mathrm{ml}$, respectively.

Donors that contained detectable levels of all $4 \mathrm{FBR}$ in their tissue (nos. 008, 010, 012, 013 and 021) also showed relatively high anthocyanin levels in their saliva. In contrast, donors with tissues that showed no anthocyanin uptake (005, 009, 018) contained low-average salivary anthocyanin levels. Similar to the saliva samples, appreciable interdonor differ-

Table V. Black Raspberry Anthocyanin Levels in Oral Mucosa (Nanograms per Milligram Protein) and Percent Anthocyanin Uptake

\begin{tabular}{|c|c|c|c|c|}
\hline Sample ID & Cyanidin 3-glucoside & Cyanidin 3-sambubioside & Cyanidin 3-rutinoside & Cyanidin 3-xylosylrutinoside \\
\hline Tissue 002 & ND $(0 \%)$ & ND $(0 \%)$ & $48.83(0.0035 \%)$ & $39.17(0.0050 \%)$ \\
\hline Tissue 004 & $24.63(0.0092 \%)$ & ND $(0 \%)$ & $62.31(0.0045 \%)$ & $36.30(0.0046 \%)$ \\
\hline Tissue 005 & ND $(0 \%)$ & ND $(0 \%)$ & ND $(0 \%)$ & ND $(0 \%)$ \\
\hline Tissue 006 & $181.09(0.0667 \%)$ & ND $(0 \%)$ & $365.45(0.0265 \%)$ & $249.82(0.0320 \%)$ \\
\hline Tissue 007 & $43.21(0.0161 \%)$ & ND $(0 \%)$ & $145.71(0.0106 \%)$ & $76.96(0.0098 \%)$ \\
\hline Tissue 008 & $48.39(0.180 \%)$ & $66.26(0.0220 \%)$ & $121.70(0.0088 \%)$ & $75.39(0.0096 \%)$ \\
\hline Tissue 009 & ND $(0 \%)$ & ND $(0 \%)$ & ND $(0 \%)$ & ND $(0 \%)$ \\
\hline Tissue 010 & $38.23(0.0143 \%)$ & $35.45(0.0118 \%)$ & $167.44(0.0121 \%)$ & $88.90(0.0113 \%)$ \\
\hline Tissue 011 & $46.00(0.0172 \%)$ & ND $(0 \%)$ & $126.63(0.0092 \%)$ & $79.50(0.0101 \%)$ \\
\hline Tissue 012 & $30.76(0.0115 \%)$ & $26.27(0.0087 \%)$ & $119.04(0.0086 \%)$ & $62.52(0.0080 \%)$ \\
\hline Tissue 013 & $28.64(0.0107 \%)$ & $20.42(0.0068 \%)$ & $177.01(0.0128 \%)$ & $55.95(0.0071 \%)$ \\
\hline Tissue 014 & $3.45(0.0013 \%)$ & ND $(0 \%)$ & $5.92(0.0004 \%)$ & $2.66(0.003 \%)$ \\
\hline Tissue 015 & ND $(0 \%)$ & ND $(0 \%)$ & $253.75(0.0184 \%)$ & $152.19(0.0194 \%)$ \\
\hline Tissue 016 & $71.28(0.0266 \%)$ & ND $(0 \%)$ & $161.28(0.0117 \%)$ & $118.80(0.0152 \%)$ \\
\hline Tissue 017 & ND $(0 \%)$ & ND $(0 \%)$ & $876.00((0.0635 \%)$ & $\mathrm{ND}(0 \%)$ \\
\hline Tissue 018 & ND $(0 \%)$ & ND $(0 \%)$ & ND $(0 \%)$ & ND $(0 \%)$ \\
\hline Tissue 019 & $417.50(0.1557 \%)$ & ND $(0 \%)$ & $936.25(0.0679 \%)$ & $671.25(0.0856 \%)$ \\
\hline Tissue 020 & $16.99(0.0063 \%)$ & ND $(0 \%)$ & $56.86(0.0041 \%)$ & $30.90(0.0039 \%)$ \\
\hline Tissue 021 & $325.78(0.1215 \%)$ & $270.16(0.0895 \%)$ & $1,393.44(0.1012 \%)$ & $703.44(0.0897 \%)$ \\
\hline Tissue 023 & $274.29(0.1023 \%)$ & ND $(0 \%)$ & $1,079.14(0.0783 \%)$ & $659.14(0.0841 \%)$ \\
\hline Mean (ng/mg all samples \pm SEM) & $77.51 \pm 26.64$ & $20.93 \pm 13.32$ & $304.84 \pm 90.15$ & $155.14 \pm 50.86$ \\
\hline Mean (ng/mg detectable only \pm SEM) & $110.73 \pm 35.73$ & $83.71 \pm 47.19$ & $358.64 \pm 427.40$ & $193.93 \pm 246.91$ \\
\hline MIN & 3.45 & 20.42 & 5.92 & 2.66 \\
\hline MAX & 417.50 & 270.16 & $1,393.44$ & 703.44 \\
\hline Fold difference & 121.11 & 13.23 & 235.34 & 264.66 \\
\hline Mean \% anthocyanin uptake + SEM & $0.0289 \pm 0.010$ & $0.0060 \pm .0045$ & $0.0221 \pm .007$ & $0.0298 \pm .007$ \\
\hline \multicolumn{5}{|c|}{ Mean \% anthocyanin uptake for all 4 FBR anthocyanins $=0.0217 \pm 0.0055$} \\
\hline
\end{tabular}

Limits of detection were $2 \mathrm{ng} / \mathrm{ml}$ for cyanidin 3-rutinoside, cyanidin 3-glucoside and cyanidin 3-xylosylrutinoside and $5 \mathrm{ng} / \mathrm{ml}$ for cyanidin 3sambubioside. (Anthocyanins (nanograms) delivered per $0.5 \mathrm{~g}$ gel: glucoside $=268,100$; sambubioside $=301,700$; rutinoside=1,378,800; xylosylrutinoside $=783,900$.) Gel application site $=$ retromolar pad

ND not detectable 
ences were noted in the tissue anthocyanin levels. The overall average of anthocyanin uptake into treated tissues was $0.0217 \%$ following a single topical FBR gel application (Table V).

Levels of FBR anthocyanins were non-detectable in the single time point, retromolar pad application plasma samples. These data confirm that $5 \mathrm{~min}$ after gel application to keratinized intact oral mucosa, the plasma levels of the respective anthocyanins were below $0.2 \mathrm{ng} / \mathrm{ml}$.

Although many of the donors' daily and intraoperative medications have reported effects (either increase or decrease) on saliva production (Table I), no statistically significant correlations between medications received and anthocyanin levels were identified.

Compartmentalization of FBR Anthocyanins Within Sali$v a$ and Tissue Samples. Levels of all four FBR anthocyanins were significantly higher in saliva relative to plasma $(p<0.001)$. Likewise, levels of cyanidin 3-rutinoside $(p<0.002)$, cyanidin 3 xylosylrutinoside $(p<0.002)$ and cyanidin 3 -glucoside $(p<0.05)$ were significantly greater in tissue relative to plasma. The majority of the donors' tissues did not contain detectable levels of cyanidin 3-sambubioside, resulting in extensive overlap between the tissue and plasma samples. Consequently, these data were not significant. In addition, the mean uptake of FBR anthocyanins into saliva was approximately 368 fold higher relative to levels achieved in tissues.

Due to their reported effects on saliva, both the daily and intraoperative medications could affect local gel clearance. Therefore, intra-donor comparisons of detectable anthocyanin levels in donor-matched saliva and tissue were also conducted. In every comparison, FBR anthocyanins were distributed at higher levels in saliva relative to donor-matched tissues ( $p<0.001$ for all four FBR anthocyanins).

Collectively, the single time point saliva, plasma and tissue data demonstrate a saliva $>$ tissue $>$ plasma distribution for FBR anthocyanins following gel application to intact, keratinized oral tissue.

Effect of Oral Mucosal Tissue Site on Anthocyanin Distribution. Results from the single time point $(5 \mathrm{~min}$ post gel application) sublingual gel application studies reveal that application site impacts anthocyanin distribution. Mean percent retention \pm SEM of the respective black raspberry anthocyanins retained in saliva were: cyanidin 3-glucoside $=$ $3.531 \pm 2.05$; cyanidin 3-sambubioside $=7.361 \pm 4.31$; cyanidin 3 rutinoside $=6.721 \pm 4.41$, cyanidin 3 -xylosylrutinoside $=5.331 \pm$ 3.03 , for an overall mean of $5.741 \pm 0.85$ anthocyanin retention in saliva. These data show that relative to the retromolar pad application site, a lower percent of gel was present in saliva following sublingual application. Further, none of the plasma samples from this experimental group contained any detectable levels of FBR anthocyanins.

Results from the time course, retromolar pad application studies (Table VI) reveal persistence of FBR anthocyanins in saliva over time. Anthocyanin levels were detectable in all donors' saliva at the $1 \mathrm{~h}$ time point. Further, two of the five donors retained detectable FBR anthocyanins in their saliva through the $4 \mathrm{~h}$ post application time point. One of these donors (TC002) demonstrated detectable levels of all four FBR anthocyanins, in the "standard" FBR anthocyanin distribution i.e. rutinoside highest, glucoside lowest, at all time points. Donor TC001's saliva profile was unique in that glucoside rather than rutinoside, represented the predominant anthocyanin at all time points. This distribution, which suggested the potential for a unique cyanindin 3-rutinoside decomposition profile, was the basis for the cyanidin 3rutinoside saliva incubation studies.

Time course plasma analyses revealed the presence of FBR anthocyanins in one (TC001) of the five donors. This donor's plasma contained levels (nanograms per milliliter) of cyanidin 3-rutinoside of $0.24(1 \mathrm{~h})$ and $0.28(4 \mathrm{~h})$ and of cyanidin 3-xylosylrutinoside $0.24(4 \mathrm{~h})$. None of the other time course donors' plasma samples contained any detectable levels of FBR anthocyanins.

Conditions Present in Human Saliva Appear to Promote Decomposition and/or Metabolism of Cyanidin 3-Rutinoside.

The cyanidin 3-rutinoside standard contains trace amounts of cyanidin 3-glucoside. Relative to the artificial saliva samples, all of the donors' saliva samples contained lower cyanidin 3glucoside levels at all time points (Table VII). Two donors (001 and 002) demonstrated low levels of cyanidin 3-rutinoside in their baseline control saliva samples. These same donors' samples $(001,002)$ showed a progressive decrease in cyanidin 3 -glucoside levels over the experimental time course. In contrast, a more erratic distribution (initial decrease, then an increase) was apparent the other donors' samples (Table VII). Appreciable interdonor variations were apparent with regard to cyanidin 3-rutinoside retention (Table VII). While some cyanidin 3-rutinoside decomposition occurred in the artificial saliva samples (recovery rate of $\sim 57 \%$ ), the levels of cyanidin 3 -glucoside and cyanidin 3-rutinoside remained constant over time. These data show that the artificial saliva samples did not demonstrate a comparable decomposition and/or metabolic conversion profile as that observed in the human saliva samples.

\section{DISCUSSION}

Results from our oral epithelial dysplasia berry gel trial demonstrated appreciable interpatient variations with regard to the extent of chemopreventive efficacy $(21,22)$. We speculate that these disparities reflect, at least in part, patient-related differences in FBR absorption and target tissue uptake. Those clinical trial findings were the basis for this current study which assessed the distribution of the $10 \%$ FBR gel in oral tissues, saliva and plasma.

Anthocyanins are the predominant black raspberry phenolic compounds (24). Previous investigations from our labs have demonstrated high chemopreventive impact in anthocyanin-enriched FBR fractions, including modulation of gene expression and suppression of pro-inflammatory enzymes $(15,24,25)$. Notably, cyanidin glycosides were identified as the FBR components responsible for inhibition of benzo $[a]$ pyrene-7,8-diol-9,10-epoxide mediated transcription factor activation (25). Consequently, FBR anthocyanins were selected as the monitored compounds in this study. It is generally accepted that anthocyanins have limited absorption from the gastrointestinal tract (27). Results from this current 
Table VI. Time Course (TC) Levels of Salivary Anthocyanins

\begin{tabular}{|c|c|c|c|c|}
\hline Sample ID & Cyanindin 3-glucoside & Cyanidin 3-sambubioside & Cyanindin 3-rutinoside & Cyanidin 3-xylosylrutinoside \\
\hline TC001 $1 \mathrm{~h}$ & $65.63(0.04 \%)$ & $9.06(0.005 \%)$ & $53.77(0.005 \%)$ & $25.57(0.004 \%)$ \\
\hline TC001 2 h & $30.59(0.02 \%)$ & ND $0 \%$ & $5.63(0.0005 \%)$ & ND $0 \%$ \\
\hline TC001 $4 \mathrm{~h}$ & $34.40(0.02 \%)$ & ND $0 \%$ & $5.38(0.0005 \%)$ & ND $0 \%$ \\
\hline TC002 $1 \mathrm{~h}$ & $112.31(0.065 \%)$ & $230.97(0.136 \%)$ & $1,895.19(0.172 \%)$ & $954.74(0.135 \%)$ \\
\hline TC002 $2 \mathrm{~h}$ & $21.29(0.012 \%)$ & $49.76(0.029 \%)$ & $401.67(0.036 \%)$ & $225.97(0.032 \%)$ \\
\hline TC002 $4 \mathrm{~h}$ & $2.97(0.002 \%)$ & $15.49(0.009 \%)$ & $68.16(0.006 \%)$ & $60.13(0.008 \%)$ \\
\hline TC003 $1 \mathrm{~h}$ & ND $(0 \%)$ & $19.60(0.012 \%)$ & $91.74(0.008 \%)$ & $35.30(0.005 \%)$ \\
\hline TC003 $2 \mathrm{~h}$ & ND $(0 \%)$ & ND $(0 \%)$ & $14.31(0.001 \%)$ & $3.30(0.0005 \%)$ \\
\hline TC003 $4 \mathrm{~h}$ & ND $(0 \%)$ & ND $(0 \%)$ & $4.30(0.0004 \%)$ & ND $(0 \%)$ \\
\hline TC004 $1 \mathrm{~h}$ & ND $(0 \%)$ & ND $(0 \%)$ & $8.40(0.0008 \%)$ & ND $(0 \%)$ \\
\hline TC004 2 h & ND (0\%) & ND (0\%) & $7.64(0.0006 \%)$ & ND (0\%) \\
\hline TC004 $4 \mathrm{~h}$ & ND $(0 \%)$ & ND $(0 \%)$ & ND $(0 \%)$ & ND $(0 \%)$ \\
\hline TC005 $1 \mathrm{~h}$ & ND $(0 \%)$ & ND $(0 \%)$ & $13.79(0.0012 \%)$ & $4.56(0.0006 \%)$ \\
\hline TC005 $2 \mathrm{~h}$ & ND $(0 \%)$ & ND $(0 \%)$ & $10.32(0.0010 \%)$ & ND $(0 \%)$ \\
\hline TC005 4 h & ND $(0 \%)$ & ND $(0 \%)$ & ND (0\%) & ND $(0 \%)$ \\
\hline
\end{tabular}

(Anthocyanins (nanograms) delivered per 0.5 g gel: glucoside $=173,700$; sambubioside $=169,700$; rutinoside $=1,104,200$; xylosylrutinoside $=$ 709,400.) Gel application sites: single time point (sublingual), time course (retromolar pad)

study, which show target tissue anthocyanin uptake and sustainability at the target site, imply that a topically applied bioadhesive gel is a plausible strategy to counteract poor systemic anthocyanin absorption.

Our results demonstrated large interdonor variations in anthocyanin uptake in saliva and tissue. These data are consistent with other human studies that evaluated tissue pharmacokinetic and distribution parameters using local intraoral delivery methods (28-31). These large interdonor variations likely reflect the extensive heterogeneity among humans regarding compound retention and uptake-modifying parameters such as rate of saliva secretion and clearance, extent of tissue keratinization and local tissue anthocyanin metabolism or decomposition.

Unique aspects of this current study, i.e. delivery formulation, compounds evaluated, short duration for the pharmacokinetic analyses, and conduction of post gel application tissue biopsies make direct comparisons to previous investigations difficult. Regardless, our average gel-mediated anthocyanin delivery values obtained in saliva $[(7.99 \%, 5 \mathrm{~min}$ post

Table VII. Effect of Incubation with Human Saliva on Cyanidin 3-Rutinoside (Cyn 3-rut) and Cyanidin 3-Glucoside (Cyn 3-glu) Levels

\begin{tabular}{|c|c|c|c|c|}
\hline Sample & Cyn 3-glu (ng/ml) & Cyn 3-rut (ng/ml) & Cyn 3-rut $(\mu \mathrm{M})$ & $\%$ recovery cyn 3 -rut \\
\hline SL 001 con & ND & 24.35 & 0.04 & NA \\
\hline SL $0011 \mathrm{~h}$ & 182.15 & $11,222.11$ & 18.86 & 37.72 \\
\hline SL $0012 \mathrm{~h}$ & 78.95 & $11,087.80$ & 18.63 & 37.27 \\
\hline SL $0014 \mathrm{~h}$ & 28.55 & $10,791.50$ & 18.14 & 36.27 \\
\hline SL002 con & ND & 32.14 & 0.05 & NA \\
\hline SL $0021 \mathrm{~h}$ & 50.17 & $2,782.75$ & 4.68 & 9.35 \\
\hline SL $0022 \mathrm{~h}$ & 11.88 & $1,158.87$ & 1.95 & 3.90 \\
\hline SL $0024 \mathrm{~h}$ & ND & 337.14 & 0.57 & 1.13 \\
\hline SL 003 con & ND & ND & ND & NA \\
\hline SL $0031 \mathrm{~h}$ & 147.84 & $6,566.43$ & 11.04 & 22.07 \\
\hline SL $0032 \mathrm{~h}$ & 37.95 & $2,361.69$ & 3.97 & 7.94 \\
\hline SL $0034 \mathrm{~h}$ & 78.22 & $8,611.56$ & 14.47 & 28.95 \\
\hline SL 004 con & ND & ND & ND & NA \\
\hline SL $0041 \mathrm{~h}$ & 42.87 & $2,193.05$ & 3.69 & 7.37 \\
\hline SL $0042 \mathrm{~h}$ & ND & 635.56 & 1.07 & 2.14 \\
\hline SL $0044 \mathrm{~h}$ & 167.74 & $8,750.34$ & 14.71 & 29.41 \\
\hline SL 005 con & ND & ND & ND & NA \\
\hline SL $0051 \mathrm{~h}$ & 12.85 & $1,244.11$ & 2.09 & 4.18 \\
\hline SL $0052 \mathrm{~h}$ & 18.10 & $1,517.49$ & 2.55 & 5.10 \\
\hline SL $0054 \mathrm{~h}$ & ND & $1,056.11$ & 1.77 & 3.55 \\
\hline AS00C con & ND & ND & ND & NA \\
\hline AS001 $1 \mathrm{~h}$ & 528.47 & $16,445.69$ & 27.64 & 55.28 \\
\hline AS001 $2 \mathrm{~h}$ & 511.27 & $17,414.73$ & 29.27 & 58.54 \\
\hline AS001 $4 \mathrm{~h}$ & 515.63 & $17,147.27$ & 28.82 & 57.64 \\
\hline
\end{tabular}

(Baseline levels prior to addition of anthocyanin standard)

$A S$ artificial saliva, $N D$ not detected, $N A$ not applicable, con control samples 
application, retromolar pad) and $(0.045 \%$, highest FBR anthocyanin, $1 \mathrm{~h}$ post application, retromolar pad)] compare favorably to results obtained in previous investigations which assessed local intraoral agent delivery. Investigations by Cardot et al. determined saliva and plasma levels of miconazole to assess local delivery efficacy of two dosing formulations of bioadhesive tablets relative to a topically applied gel (29). The mean saliva levels obtained by topical gel application in the Cardot study were $0.74 \%$ (29). While the Cardot et al. compound uptake was assessed at $30 \mathrm{~min}$ post application, our data were collected at $5 \mathrm{~min}$ and $1 \mathrm{~h}$ time points. Studies by Sobeck et al., which investigated levels of vitamin A derivatives in buccal keratinocytes following use of a retinyl palmitate containing toothpaste, determined approximately $0.1 \%$ of the applied dose (approximately five fold greater than our tissue uptake) was internalized by oral keratinocytes (28). Differences between the Sobeck and this current study include: formulation (toothpaste versus bioadhesive gel), dosing duration (56 days versus single application), tissues evaluated (superficial differentiated keratinocytes versus intact oral mucosa) and solubility of the targeted compound [vitamin A (fat soluble) and anthocyanins, (water soluble)] (28).

Three donors' tissues did not contain any detectable levels of FBR anthocyanins. While all of these individuals' saliva contained all four FBR anthocyanins, their salivary anthocyanin levels were low to average. Also, one of these donors (STP005) had the second highest saliva volume, which would have an overall diluting effect and facilitate gel clearance. With regard to compound uptake and penetration, oral mucosa is intermediate between gastric mucosa (more permeable) and skin (less permeable) (32). Modulating factors for oral tissue compound uptake include degree of keratinization, extent and chemical nature of inter-epithelial cell lipid packaging, tissue biofilm and associated bacteria (surfactant and/or anthocyanin metabolism properties), salivary flow and clearance and relative number of tight junctions (33). It is also necessary to consider the contributions of the $\mathrm{Na}^{+}$-dependent glucose transporter (SGLT1) as well as the multidrug resistance protein 2 (MRP2) when assessing intracellular anthocyanin levels as these systems have been shown to affect anthocyanin cellular uptake and export, respectively (27,34-36). The absence of anthocyanins in these three donors' tissues could reflect the effects of one or more of the variables cited above. Finally, the results from the tissue processing-anthocyanin studies, which showed lower anthocyanin recovery from tissues with the lower, analogous to tissue sample concentrations, suggest that our data underestimate tissue anthocyanin levels following gel application.

In this current study, plasma levels of anthocyanins were only detectable in one time course donor (TC001). In contrast, Lawrence et al.'s study demonstrated that even the lowest gel dose ( $0.5 \%$ ketoprofen, $5 \mathrm{mg}$ b.i.d. for 14.5 days $)$ resulted in plasma ketoprofen levels (30). Obvious differences between the Lawrence and this current study include application site: (periodontally inflamed tissues which have increased vascularity and may have microulcerations relative to intact, keratinized oral mucosa) and dosing frequency (multiple doses over time versus single application) (30). Unlike our previous findings, which demonstrated plasma anthocyanin levels $5 \mathrm{~min}$ after gel application (20), this current study did not detect any plasma anthocyanin levels following gel application to the same site i.e. sublingual. These data imply that a more basic $\mathrm{pH}$ (prototype gel $\mathrm{pH}$ 6.5, clinical trial and this study gel $\mathrm{pH}$ 3.5) enhances gel penetrative capacities, potentially by facilitating paracellular anthocyanin transport. Our results show a relatively rapid time course for FBR gel penetration in human oral mucosa i.e., 5 min following sublingual administration of the prototype $\mathrm{pH} 6.5$ gel (20) and $1 \mathrm{~h}$ following application to keratinized tissues (TC001). In contrast, previous studies that employed an in vitro model of oral epithelium showed a much slower penetration of the tested compounds (37). These disparate results likely reflect experimental differences that include tissues evaluated (intact oral mucosa relative to an in vitro model), method of administration (topical application by rubbing the gel in situ versus addition into media), presence or absence of circulation and salivary flow, and presence or absence of a mucoadhesive vehicle.

The time course saliva results showed cyanidin 3glucoside as the predominant anthocyanin in one donor. Although the time course saliva incubation studies demonstrated variable cyanidin 3-glucoside levels over time in three donors' samples, these data are not convincing evidence to support conversion of cyanidin 3-rutinoside to cyanidin 3glucoside. These findings, in conjunction with the results that showed a greater number of tissues retained cyanidin 3glucoside relative to cyanidin 3-sambubioside (which is contained at higher levels in FBR) suggest a higher persistence of the monosaccharide cyanidin 3-glucoside relative to the other three FBR anthocyanins in some persons.

The extent of cyanidin 3-rutinoside recovery was appreciably lower in human saliva samples relative to artificial saliva. These data are consistent with the presence of glycosidases in human saliva that are capable of hydrolyzing flavonoid glycosides to the more chemopreventive-effective aglycones (38). These previous studies also demonstrated a large interdonor variability in glycosidase activities (38). As the cyanidins are superior antioxidants, interpatient differences in glycosidase activities may be at least partially responsible for our observed variations in chemopreventive efficacy $(21,22)$. In addition to glycosidases, other anthocyanin metabolizing enzymes include catechol- $O$-methyltransferase, uridine diphosphate (UDP)-glucuronosyl transferase and UDP-glc-dehydrogenase $(27,34)$. Previous studies from our labs demonstrated that methylation is the predominant anthocyanin metabolizing pathway following oral FBR administration to humans (39). Anthocyanins can also undergo decomposition, which entails formation of the corresponding phenolic acid from the B-ring of the anthocyanin skeleton (40). While the more complex di and trisaccharide anthocyanins are considered less degradation-susceptible than their monosaccharide counterparts, our data suggest that conditions present in human saliva promote decomposition and/or metabolism of the disaccharide cyanidin 3-rutinoside.

While previous oral cavity chemoprevention trials monitored a wide variety of therapeutic outcomes including clinical and microscopic appearances, and molecular parameters such as loss of heterozygosity indices or DNA ploidy (8-14), none of these studies assessed pharmacokinetic parameters or local tissue distribution. The key findings of this current study i.e. marked donor-specific variations in agent uptake, 
sustainability of therapeutic compounds at the target site, demonstration of target tissue uptake and data consistent with anthocyanin decomposition and/or metabolism in the oral environment have implications that could affect clinical efficacy. We anticipate that these data, in conjunction with complementary metabolism studies, will provide beneficial insights that will advance oral cavity chemoprevention.

\section{ACKNOWLEDGEMENTS}

This work was supported by NIH grants R21 CA132138 (Mallery), R41 AT003342 (Mallery) and USDA grants 3890303560 (Stoner) and 34501-13965 (Stoner). The NIH R41 (STTR) grant was awarded to NanoMed Pharmaceuticals, Inc. Dr. Mallery served as the principle investigator on the STTR grant and is a member of the scientific advisory board for NanoMed Pharmaceuticals. Dr. Mumper is a founder and a Director of NanoMed. The authors also express their appreciation to Ms. Ashley Jones for her contributions in both the clinical and technical aspects of this project.

Open Access This article is distributed under the terms of the Creative Commons Attribution Noncommercial License which permits any noncommercial use, distribution, and reproduction in any medium, provided the original author(s) and source are credited.

\section{REFERENCES}

1. B. W. Neville, and T. A. Day. Oral cancer and precancerous lesions. CA: Cancer. J. Clin. 52:195-215 (2002).

2. A. A. Forastiere. Head and neck cancer: overview of recent developments and future direction. Semin. Oncol. 27:1-4 (2000).

3. L. J. Wirth, and M. R. Posner. Recent advances in combined modality therapy for locally advanced head and neck cancer. Curr. Cancer Drug Targets. 7:674-680 (2007). doi:10.2174/ 156800907782418329.

4. A. Jemal, R. Siegel, E. Ward, T. Murray, J. Xu, and M. J. Thun. Cancer statistics, 2007. CA, A Cancer Journal for Clinicians. 57:43-66 (2007).

5. S. Silverman Jr., M. Gorsky, and F. Lozada. Oral leukoplakia and malignant transformation. A follow-up study of 257 patients. Cancer. 53:563-568 (1984). doi:10.1002/1097-0142(19840201) 53:3<563::AID-CNCR2820530332>3.0.CO;2-F.

6. J. J. Scuibba. Oral leukoplakia. Crit. Rev. Oral Biol. Med. 6:147160 (1995).

7. M. B. Sporn. Approaches to prevention of epithelial cancer during the preneoplastic period. Cancer Res. 36:2699-2702 (1976).

8. S. M. Lippman, J. J. Lee, J. W. Martin, A. K. EI-Naggar, X. Xu, D. M. Shin, M. Thomas, L. Mao, H. A. Fritsche Jr., X. Zhou, V. Papadimitrakopoulou, F. R. Khuri, H. Tran, G. L. Clayman, W. N. Hittelman, W. K. Hong, and R. Lotan. Fenretinide activity in retinoid-resistant oral leukoplakia. Clin. Cancer Res. 12:3109_ 3114 (2006). doi:10.1158/1078-0432.CCR-05-2636.

9. S. Toma, S. Benso, E. Albanese, R. Palumbo, E. Cantoni, G. Nicolò, and P. Mangiante. Treatment of oral leukoplakia with beta-carotene. Oncology. 49:77-81 (1992).

10. S. M. Lippman, J. G. Batsakis, B. B. Toth, R. S. Weber, J. J. Lee, J. W. Martin, G. L. Hays, H. Goepfert, and W. K. Hong. Comparison of low-dose isotretinoin with beta carotene to prevent oral carcinogenesis. N. Engl. J. Med. 328:15-20 (1993). doi:10.1056/NEJM199301073280103.

11. V. A. Papadimitrakopoulou, G. L. Clayman, D. M. Shin, J. N. Myers, A. M. Gillenwater, H. Goepfert, A. K. EI-Naggar, J. S. Lewin, S. M. Lippman, and W. K. Hong. Biochemoprevention for dysplastic lesions of the upper aerodigestive tract. Arch. Otolaryngol. Head Neck Surg. 125:1083-1089 (1999).

12. D. M. Shin, L. Mao, V. M. Papadimitrakopoulou, G. Clayman, A. EI-Naggar, H. J. Shin, J. J. Lee, J. S. Lee, A. Gillenwater, J. Myers, S. M. Lippman, W. N. Hittelman, and W. K. Hong. Biochemopreventive therapy for patients with premalignant lesions of the head and neck and p53 gene expression. J. Natl. Cancer Inst. 92:69-73 (2000). doi:10.1093/jnci/92.1.69.

13. C. M. Rudin, E. E. Cohen, V. A. Papadimitrakopoulou, S. Silverman Jr., W. Recant, A. K. EI-Naggar, K. Stenson, S. M. Lippman, W. K. Hong, and E. E. Vokes. An attenuated adenovirus, ONYX-015, as mouthwash therapy for premalignant oral dysplasia. J. Clin. Oncol. 21(24):4546-4552 (2003). doi:10.1200/JCO.2003.03.544. Dec 15.

14. J. L. Mulshine, J. C. Atkinson, R. O. Greer, V. A. Papadimitrakopoulou, C. Van Waes, S. Rudy, J. W. Martin, S. M. Steinberg, D. J. Liewehr, I. Avis, R. I. Linnoila, S. Hewitt, S. M. Lippman, R. Frye, and P. F. Cavanaugh Jr. Randomized, double-blind, placebo-controlled phase IIB trial of the cyclooxygenase inhibitor ketorolac as an oral rinse in oropharyngeal leukoplakia. Clin. Cancer Res. 10:1565-1573 (2004). doi:10.1158 1078-0432.CCR-1020-3.

15. K. A. Rodrigo, Y. Rawal, R. J. Renner, S. J. Schwartz, Q. Tian, P. E. Larsen, and S. R. Mallery. Suppression of the tumorigenic phenotype in human oral squamous cell carcinoma cells by an ethanol extract derived from freeze-dried black raspberries. Nutr. Cancer. 54:58-68 (2006). doi:10.1207/s15327914nc5401_7.

16. C. Huang, J. Li, L. Song, D. Zhang, Q. Tong, M. Ding, L. Bowman, R. Aziz, and G. D. Stoner. Black raspberry extracts inhibit benzo(a)pyrene diol-epoxide-induced activator protein 1 activation and VEGF transcription by targeting the phosphotidylinositol 3-kinase/Akt pathway. Cancer Res. 66:581-587 (2006). doi:10.1158/0008-5472.CAN-05-1951.

17. T. Chen, M. E. Rose, H. Hwang, R. G. Nines, and G. D. Stoner. Black raspberries inhibit Ninitrosomethylbenzylamine (NMBA)induced angiogenesis in rat esophagus parallel to the suppression of COX-2 and iNOS. Carcinogenesis. 27:2301-2307 (2006). doi:10.1093/carcin/bgl109.

18. H. Lu, J. Li, D. Zhang, G. D. Stoner, and D. Huang. Molecular mechanisms involved in chemoprevention of black raspberry extracts: from transcription factors to their target genes. Nutrition and Cancer. 54:69-78 (2006). doi:10.1207/ s15327914nc5401 8 .

19. T. Chen, H. Hwant, M. E. Rose, R. G. Nines, and G. D. Stoner. Chemopreventive properties of black raspberries in $\mathrm{N}$-nitrosomethylbenzylamine-induced rat esophageal tumorigenesis: down-regulation of cyclooxygenase-2, inducible nitric oxide synthase, and c-Jun. Cancer Res. 66:2853-2859 (2006). doi:10.1158/0008-5472.CAN-05-3279.

20. S. R. Mallery, G. D. Stoner, P. E. Larsen, H. W. Fields, K. A. Rodrigo, S. J. Schwartz, Q. Tian, J. Dai, and R. J. Mumper. Formulation and in-vitro and in-vivo evaluation of a mucoadhesive gel containing freeze dried black raspberries: implications for oral cancer chemoprevention. Pharm. Res. 24:728-737 (2007). doi:10.1007/s11095-006-9192-1.

21. B. S. Shumway, L. A. Kresty, P. E. Larsen, J. C. Zwick, B. Lu, H. W. Fields, R. J. Mumper, G. D. Stoner, and S. R. Mallery. Effects of a topically applied bioadhesive berry gel on loss of heterozygosity indices in premalignant oral lesions. Clin. Cancer Res. 14:2421-2430 (2008). doi:10.1158/1078-0432.CCR-07-4096.

22. S. R. Mallery, J. C. Zwick, P. Pei, M. Tong, P. E. Larsen, B. S. Shumway, B. Lu, H. W. Fields, R. J. Mumper, and G. D. Stoner. Topical application of a bioadhesive black raspberry gel modulates gene expression and reduces cyclooxygenase 2 protein in human premalignant oral lesions. Cancer Res. 68:4945-4947 (2008). doi:10.1158/0008-5472.CAN-08-0568.

23. O. H. Lowry, N. J. Rosebrough, A. L. Farr, and R. J. Randall Protein measurement with the Folin phenol reagent. J. Biol. Chem. 193:265-275 (1951).

24. D. Stoner Gary, and L.-S. Wang. Anthocyanins and their role in cancer prevention. Cancer Lett. 269:281-290 (2008). doi:10.1016/ j.canlet.2008.05.020.

25. S. S. Hecht, C. Huang, G. D. Stoner, J. Li, P. M. J. Kenney, S. J. Sturla, and S. G. Carmella. Identification of cyanidin glycosides as constituents of freeze-dried black raspberries which inhibit 
anti-benzo[a]pyrene-7,8-diol-9,10-epoxide induced $\mathrm{NFkB}$ and AP-1 activity. Carcinogenesis. 27:1617-1626 (2006). doi:10.1093/ carcin/bgi366.

26. G. D. Stoner, C. Sardo, G. Apseloff, D. Mullet, W. Wargo, V. Pound, A. Singh, J. Sanders, R. Aziz, B. Casto, and X. Sun. Pharmacokinetics of anthocyanins and ellagic acid in healthy volunteers fed freeze-dried black raspberries daily for 7 days. $J$. Clin. Pharmacol. 45:1153-1164 (2005). doi:10.1177/ 0091270005279636.

27. T. Walle. Flavonoids and isoflavones (Phytoestrogens): absorption, metabolism and bioactivity. Free Rad. Biol. Med. 36:829837 (2004). doi:10.1016/j.freeradbiomed.2004.01.002.

28. U. Sobeck, A. Fischer, and H. K. Blesalski. Uptake of vitamin A in buccal mucosal cells after topical application of retinyl palmitate: a randomized, placebo-controlled and double blind trial. Br. J. Nutrition. 90:69-74 (2003). doi:10.1079/BJN2003854.

29. J.-M. Cardot, C. Chaumont, C. Dubray, D. Costantini, and J.-M. Aiache. Comparison of the pharmacokinetics of miconazole after administration via a bioadhesive slow release tablet and an oral gel to healthy male and female subjects. Br. J. Clin. Pharmacol. 58:345-351 (2004). doi:10.1111/j.1365-2125.2004.02154.x.

30. H. P. Lawrence, D. W. Paquette, P. C. Smith, G. Maynor, R. Wilder, G. L. Mann, T. Binder, E. Troullos, M. Annett, M Friedman, and S. Offenbacher. Pharmacokinetic and safety evaluations of ketoprofen gels in subjects with adult periodontitis. J. Dent. Res. 77:1904-1912 (1998).

31. T. C. Dowling, M. Arjomand, E. T. Lin, L. V. Allen, and M. L. McPherson. Relative bioavailability of ketoprofen $20 \%$ in a poloxamer-lecithin organogel. Am. J. Health-Syst. Pharm. 61:2541-2544 (2004).

32. Y. Rojanasakul, L.-Y. Wang, M. Bhat, D. D. Glover, C. J. Malanga, and J. K. Ma. The transport barrier of epithelial: a comparative study on membrane permeability and charge selectivity in the rabbit. Pharm. Res. 9:1029-1034 (1992). doi:10.1023/A:1015802427428.

33. J. A. Nicolazzo, B. L. Reed, and B. C. Finnin. Buccal penetration enhancers-how do they really work? J. Control Release. 105:115 (2005). doi:10.1016/j.jconrel.2005.01.024.

34. R. L. Prior, and X. Wu. Anthocyanins: structural characteristics that result in unique metabolic patterns and biological activities. Free Rad. Res. 40:1014-1028 (2006). doi:10.1080/1071576060 0758522.

35. T. Kimura, H. Yamano, A. Tanaka, T. Matsummura, M. Ueda, K. Ogawara, and K. Higaki. Transport of D-glucose across cultured stratified cell layer of human oral mucosal cells. J. Pharm. Pharmacol. 54:213-219 (2002). doi:10.1211/0022357021778402.

36. R. A. Walgren, J. K. Karnaky, G. E. Lindemayer, and T. Walle. Efflux of dietary flavonoid quercetin $4^{\prime} \beta$-glucoside across human intestinal Caco-2 cell monolayers by apical multidrug resistanceassociated protein-2. J. Pharmacol. Exp. Ther. 294:830-836 (2000).

37. T. Walle, U. K. Walle, D. Sedmera, and M. Klausner. Benzo[a] pyrene-induced oral carcinogenesis and chemoprevention: Studies in bioengineered human tissue. Drug Metab. Disp. 34:346-350 (2006).

38. T. Walle, A. M. Browning, L. L. Steed, S. G. Reed, and U. K. Walle. Flavonoid glucosides are hydrolyzed and thus activated in the oral cavity. J. Nutr. 135:48-52 (2005).

39. Q. Tian, M. M. Giusti, G. D. Stoner, and S. J. Schwartz. Urinary excretion of black raspberry (Rubus occidentalis) anthocyanins and their metabolites. J. Agric. Food Chem. 54:1467-1472 (2006). doi:10.1021/jf052367z.

40. J. Fleschhut, F. Kratzer, G. Rechkemmer, and S. E. Kulling. Stability and biotransformation of various anthocyanins in vitro. Eur. J. Nutr. 45:7-18 (2006). doi:10.1007/s00394-005-0557-8. 